expression (MFI) of CD25+ cells was then monitored after two days by flow cytometry.

Results $1,25(\mathrm{OH})_{2} \mathrm{D}_{3}$ significantly increased CTLA4 MFI in both healthy and latent populations following stimulation with SEB $(\mathrm{p} \leq 0.01)$ or PPD $(\mathrm{P}=0.026,0008) .25(\mathrm{OH}) \mathrm{D}_{3}$ also enhanced CTLA-4 expression in SEB cultures ( $p \leq 0.01)$. Induction of CTLA-4 was however reduced in PPD cultures (median 121) compared to SEB (median 360). Interestingly, the magnitude of CTLA-4 induction by $1,25(\mathrm{OH})_{2} \mathrm{D}_{3}$ or $25(\mathrm{OH}) \mathrm{D}_{3}$ also differed for healthy and latent populations in response to $\operatorname{SEB}\left(1,25(\mathrm{OH})_{2} \mathrm{D}_{3}(\mathrm{p}=0.01)\right.$ and $25(\mathrm{OH}) \mathrm{D}_{3}$ $(p=0.006)$, with a similar trend in PPD stimulated cells $(p=0.092)$.

Conclusion The shift towards a $T$ reg population as a result of vitamin $\mathrm{D}$ is blunted in latent TB compared to health. Differential response of memory cells in latent disease could account for this.

1. Jeffery, LE, et al., 1,25-Dihydroxyvitamin D3 and IL-2 combine to inhibit $T$ cell production of inflammatory cytokines and promote development of regulatory T cells expressing CTLA-4 and FoxP3. Journal of immunology, 2009. 183(9): p. 5458-67.

\section{S4 ANTI-INFLAMMATORY EFFECTS OF VITAMIN D ARE INFLUENCED MORE BY GENETIC BACKGROUND THAN MYCOBACTERIAL INFECTION}

doi:10.1136/thoraxjnl-2012-202678.010

G Hawthorne, H Mujakperuo, S Lax, L McGowan, H Kunst, D Thickett, A Turner. 'School of Clinical and Experimental Medicine, University of Birmingham, Birmingham, UK

Introduction Although vitamin D has antimicrobial effects that may be beneficial in mycobacterial infection, supplementation trials have been disappointing [1]. Response to vitamin D is heterogeneous, perhaps due to genetic variants in the vitamin $\mathrm{D}$ axis (vitamin $\mathrm{D}$ binding protein; $G C$ or vitamin $\mathrm{D}$ receptor; $V D R$ ). We aimed to assess stability and magnitude of anti-inflammatory effect of vitamin $\mathrm{D}$ in vitro in mycobacterial infection and health, and the influence of GC and VDR variants.

Methods Peripheral blood monocytes from healthy controls $(n=20)$ and patients with mycobacterial infection $(n=8)$ were cultured and incubated with LPS $(100 \mathrm{ng} / \mathrm{ml}), 25(\mathrm{OH}) \mathrm{D}_{3}(50 \mathrm{nmol})$ and $1,25(\mathrm{OH})_{2} \mathrm{D}_{3}(50 \mathrm{nmol})$. IL6 in cell supernatants was measured by ELISA. Taqman was used to type 4 SNPs: rs7041 \& rs4588 (GC), rs2228570 \& rs1544410 (VDR). The effect of the protein product of GC in culture was assessed by addition of plasma and subsequent Luminex array.

Results Change in IL6 between pairs of repeated cultures did not vary $(p=0.21)$, indicating stability of response to LPS. There was no difference between $\mathrm{HCs}$ and patients in response to vitamin $\mathrm{D}$ (both $p>0.32$ ), however in both groups there were responders $(n=7$ controls, $\mathrm{n}=5 \mathrm{~TB}$ ), in whom IL6 fell with addition of vitamin $\mathrm{D}$ $(1,25 \mathrm{D}, \mathrm{p}=0.001 ; 25 \mathrm{D}, \mathrm{p}=0.02)$ and non-responders $(\mathrm{n}=11$ controls, $\mathrm{n}=3 \mathrm{~TB})$ in whom it did not.

Response to $1,25 \mathrm{D}$ was influenced by rs7041 ( $\mathrm{T}$ allele; $\mathrm{p}=0.04$ ), and tended to associate with GC2 ( $p=0.06)$. Response to 25D was not affected by genotype until plasma was added when $G C$ haplotype appeared to have an effect. There was no influence of $V D R$ SNPs.

Conclusion Anti-inflammatory effects of vitamin $\mathrm{D}$ are influenced by GC genotype in vitro, consistent with previous mouse work [2], however it is unclear whether this occurs in humans in vivo. Such effects are equally relevant in health and mycobacterial infection. Further work to characterise changes in LPS responsiveness following high dose vitamin D replacement is ongoing.

1. Martineau AR, et al. Lancet. (2011) 377:242-50.

2. Zella LA, et al. Endocrinology. (2008) 149:3656-67.
MOLECULAR IMMUNODIAGNOSIS OF TB INFECTION: A PILOT STUDY

doi:10.1136/thoraxjnl-2012-202678.011

${ }^{1} \mathrm{DW}$ Connell, ${ }^{1} \mathrm{~A}-\mathrm{K}$ Reuschl, ${ }^{1} \mathrm{C}$ Wenden, ${ }^{2} \mathrm{M}$ Witkowski, ${ }^{3} \mathrm{OM}$ Kon, ${ }^{2} \mathrm{P}$ Klenerman, 'A Lalvani. 'Tuberculosis Research Unit, NHLI, Imperial College London, London, United Kingdom; ' NIHR Biomedical Research Centre, Peter Medawar Building, University of Oxford, Oxford, United Kingdom; ${ }^{3}$ Department of Chest and Allergy, St Mary's Hospital; Imperial College Healthcare NHS Trust, London, United Kingdom

Introduction Current interferon-gamma (IFN- $\gamma$ ) release assays (IGRAs) are not sufficiently sensitive to be used as a "rule-out" test for tuberculosis (TB). Antigen-specific gene expression of chemokines downstream of, and amplified by, IFN- $\gamma$ might demonstrate such sensitivity, and can be performed with very small volumes of blood. ${ }^{1}$

Here we assess the performance and sensitivity of two IFN- $\gamma$ dependent gene expression platforms in the peripheral blood mononuclear cells of individuals with and without TB.

Methods 23 individuals with active TB, 12 individuals with latent TB infection (LTBI), and 18 controls had simultaneous IFN- $\gamma$ ELISpot assays and qRTPCR of CXCL-9 and CXCL-10, following stimulation with the immunodominant antigens ESAT-6, CFP-10 and EspC ( 6 gene expression assays in total). Test performances of the 6 gene expression assays were compared to the ELISpot.

Results Gene expression of CXCL-9 and CXCL-10 was antigen specific, correlating well with each other and with the IFN- $\gamma$ ELISpot (Spearman Rank Correlations ranging from $r=0.648$ to 0.74). Gene expression of either was not significantly different between those with active TB and LTBI.

Receiver-operating characteristic curves indicated good test performances for all the gene expression assays (AUC ranging from 0.918 to 0.959 ) and agreements between the ELISpot and gene expression platforms was good ( $\kappa$ statistic ranging from 0.403-0.496).

After constructing cut-offs for sensitivity for individual antigens, with cut-offs for specificity matching or exceeding that of the IFN- $\gamma$ ELISpot, the sensitivity of TB diagnosis with gene expression was superior to ELISpot in 5 out of the 6 assays, although these differences were not statistically significant. Sensitivity was equivalent when antigens were combined, as in the commercially available T-Spot ${ }^{\circledast}$.TB. Conclusions These pilot data indicate that gene expression of IFN- $\gamma$-dependent cytokines is a robust, sensitive and specific method of TB diagnosis, and carries potential to be a more sensitive platform that the current gold standard - IFN- $\gamma$ ELISpot. Larger studies with appropriate power are now required in similar populations to investigate this approach definitively.

References

1. Kasprowicz VO, Mitchell JE, Chetty S, Govender P et al. A molecular assay for sensitive detection of pathogen-specific T-cells. PLoS One. 2011; 6(8):e20606. Epub 2011 Aug 11.

\section{Targets for asthma therapy}

\section{S6 THE FENOTYPE TRIAL: INHALED CORTICOSTEROID DOSE- RESPONSE USING DOMICILIARY EXHALED NITRIC OXIDE IN PERSISTENT ASTHMA}

doi:10.1136/thoraxjnl-2012-202678.012

WJ Anderson, PM Short, PA Williamson, BJ Lipworth. University of Dundee, Dundee, United Kingdom

Background International guidelines advocate a standard approach to asthma management for all despite its heterogeneity. 'Personalised' treatment for inflammatory asthma phenotypes confers superior benefits. We wished to evaluate dose-response to inhaled corticosteroids (ICS) in asthmatics with an elevated exhaled nitric oxide (FeNO) phenotype using domiciliary measurements. 
Methods We performed a randomised, cross-over trial in 21 mildto-moderate persistent asthmatics receiving ICS with elevated FeNO $(>30 \mathrm{ppb})$ that increased further $(>10 \mathrm{ppb})$ after ICS washout. Patients were randomised to 2 weeks of either fluticasone propionate $50 \mu \mathrm{g}$ twice-daily (FP100) or $250 \mu \mathrm{g}$ twice-daily (FP500). The primary outcome was response in diurnal domiciliary FeNO levels. Secondary outcomes included: mannitol challenge; serum eosinophilic cationic protein (ECP); blood eosinophil count; and asthma control questionnaire (ACQ).

Results We found significant dose-related reductions of diurnal FeNO compared to baseline - morning FeNO: baseline $=71 \mathrm{ppb}$ (95\%CI:61-83ppb); FP100=34ppb (95\%CI:29-40ppb), p <0.001; FP500 $=27 \mathrm{ppb}$ (95\%CI:22-33ppb), p<0.001; and significant dose separation for morning, $p<0.05$, and evening, $p<0.001$. Time series FeNO displayed exponential decay (Figure 1): FP100 R² $=0.913$, halflife $=69 \mathrm{hrs}$ (95\%CI:50-114hrs); FP500 R²=0.966, half-life $=55 \mathrm{hrs}$ (95\%CI:45-69hrs); as well as diurnal variation. ACQ showed significant improvements exceeding the minimal important difference $(>0.5)$ with values in keeping with controlled asthma $(<0.75)$ after each dose: FP100 $=0.48$ (95\%CI:0.24-0.71), p $=0.004 ;$ FP500 $=0.37$ (95\%CI:0.18-0.57), $p=0.001$. All other secondary inflammatory related outcomes (mannitol, ECP and eosinophils) showed significant improvements from baseline but no dose separation.

Conclusions There is a significant dose-response of diurnal FeNO to ICS in asthmatics with an elevated FeNO phenotype, which translates into well-controlled asthma. Further interventional studies are warranted using domiciliary $\mathrm{FeNO}$ in this specific phenotype.

\section{S7 INFLUENCE OF BETA-2 ADRENOCEPTOR GENOTYPE ON RESPONSE TO REGULAR RACEMIC OR LEVOSALBUTAMOL IN STEROID TREATED ASTHMATICS}

doi:10.1136/thoraxjnl-2012-202678.013

WJ Anderson, PM Short, PA Williamson, AE Morrison, CNA Palmer, R Tavendale, BJ Lipworth. University of Dundee, Dundee, United Kingdom

Background Asthmatic patients receiving inhaled corticosteroids often take frequent add-on therapy with albuterol despite ondemand prescription. We wished to evaluate trough methacholine airway hyper-responsiveness (the primary outcome) following regular treatment with racemic salbutamol and levosalbutamol compared to placebo, in steroid treated asthmatics stratified according to beta-2 adrenoceptor 16 genotype.

Methods We performed a randomised, double-blind, placebocontrolled, triple crossover trial comparing 2 weeks of regular ther-

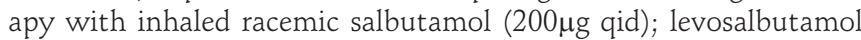
$\left(100 \mu \mathrm{g}\right.$ qid); or placebo on methacholine $\mathrm{PC}_{20} 6$ hours post dose in 30 persistent asthmatics (15 homozygous Arg16 and Gly16) receiving inhaled corticosteroids.

Results There was no rebound worsening of trough airway hyperresponsiveness to methacholine after chronic exposure to either racemic $(p=0.53)$ or levosalbutamol $(p=0.84)$ compared to placebo; nor between genotypes - as doubling dilution (dd) difference in methacholine $\mathrm{PC}_{2} 0$ from placebo (Figure 1): salbutamol/Arg16= $0.36 \mathrm{dd}$ (95\% CI: -0.43 , 1.15); salbutamol/Gly16=0.01dd (95\% CI: -0.47, 0.49); levosalbutamol/Arg16=-0.01dd (95\% CI: $-0.89,0.87$ ); levosalbutamol/Gly16 $=0.28 \mathrm{dd}(95 \% \mathrm{CI}:-0.22,0.77)$. Both active treatments improved morning PEF in Gly16 $(p=0.04)$ but not Arg16 patients $(p=0.50)$; while evening PEF improved in both Gly16 $(p<0.001)$ and Arg16 patients $(p=0.006)$.

Conclusions Chronic exposure to either racemic or levosalbutamol added to inhaled corticosteroids did not cause rebound worsening of airway hyper-responsiveness at trough compared to placebo; with no difference seen between beta-2 adrenoceptor 16 genotypes.

\section{S8 CAN EOSINOPHIL AND NEUTROPHIL MIGRATION BE THE KEY TO PHENOTYPING ASTHMA?}

doi:10.1136/thoraxjn-2012-202678.014

'JJ Lukawska, 'L Livieratos, 'B Sawyer, 'T Lee, 'M O'Doherty, 'M Kofi, 'J Ballinger, ${ }^{2} \mathrm{G}$ Gnanasegeran, ${ }^{2} \mathrm{E}$ O'Young, ' $\mathrm{C}$ Corrigan, 'G Mullen; ${ }^{1} \mathrm{King}$ 's College London, London, UK; 'uy's and St Thomas' Hospital NHS Foundation Trust, London, UK

Introduction To date, our knowledge of in vivo migration of neutrophils and eosinophils in homeostasis and disease states is based on granulocytes. Here we present a pilot study using purified human eosinophils or neutrophils and demonstrate their differential in vivo kinetics in asthmatic and healthy volunteers. Methods: On two separate occasions $100 \mathrm{ml}$ of blood was obtained from eight human

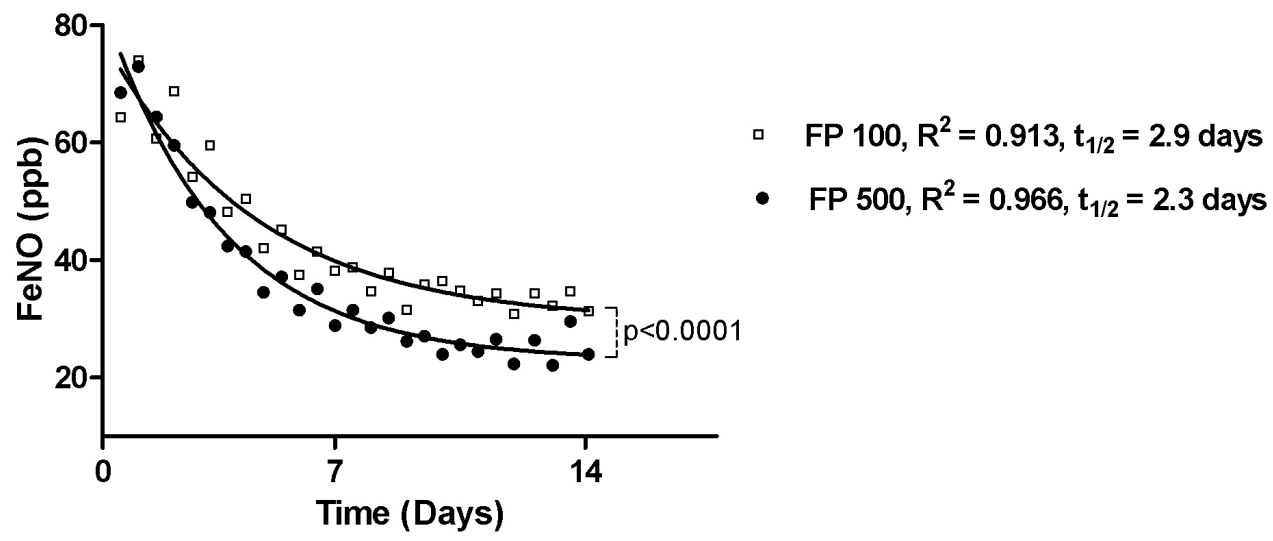

Time series morning and evening exhaled tidal nitric oxide (FeNO) values and one-phase exponential decay curves. FeNO values displayed as geometric means at each sequential time point for each group. $R^{2}=$ coefficient of determination (goodness of fit) of exponential decay curves to each data set. $t_{1 / 2}=$ half-life of exponential decay. $p p b=$ parts per billion .

Abstract S6 Figure 1 